\title{
Flora das cangas da Serra dos Carajás, Pará, Brasil: Oxalidaceae
}

\author{
Flora of the cangas of Serra dos Carajás, Pará, Brazil: Oxalidaceae
}

\author{
Climbiê Ferreira Hall ${ }^{1,3}$, Julia Meirelles ${ }^{1} \&$ Pedro Fiaschi $^{2}$
}

\begin{abstract}
Resumo
Apresentamos o tratamento taxonômico de Oxalidaceae para as cangas da Serra dos Carajás (Pará, Brasil). Foram registradas duas espécies: Oxalis barrelieri e $O$. mucronulata. São apresentadas descrições, comentários e ilustrações das espécies.
\end{abstract}

Palavras-chave: FLONA Carajás, taxonomia, Oxalis.

\begin{abstract}
We present the taxonomic treatment of Oxalidaceae for the cangas of Serra dos Carajás (Pará state, Brazil). Two species were recorded: Oxalis barrelieri and O. mucronulata. Descriptions, comments and illustrations of the species are presented.
\end{abstract}

Key words: FLONA Carajás, taxonomy, Oxalis.

\section{Oxalidaceae}

Oxalidaceae R.Br. compreende cinco gêneros e ca. 565 espécies (Mabberley 2008), com distribuição cosmopolita e predomínio nas regiões tropicais e subtropicais (Stevens 2001 em diante). A família é constituída por ervas, subarbustos, arbustos ou árvores com folhas alternas ou subopostas, compostas, reflexas durante a noite; folíolos iguais ou desiguais, simétricos ou assimétricos, margens inteiras. As inflorescências são axilares, cimosas ou as flores são solitárias, monoclinas, actinomorfas, diclamídeas, pentâmeras, hipóginas e normalmente heterostílicas. Os frutos são cápsulas loculicidas ou bagas geralmente 5-lobados e as sementes são normalmente ariladas, com endosperma carnoso (adaptado de Progel 1877; Lourteig 1980; Aymard \& Berry 2003; Fiaschi \& Conceição 2005). No Brasil são confirmadas 103 espécies distribuídas nos gêneros Biophytum DC. e Oxalis L., além do gênero da carambola, Averrhoa L., que é introduzido (Fiaschi et al. 2013; BFG 2015). $\mathrm{Na}$ Serra dos Carajás foi registrado apenas o gênero Oxalis.

\section{Oxalis L.}

Oxalis é constituído por ervas, subarbustos ou arbustos com folhas normalmente alternas e 3-folioladas, pinadas ou digitadas. As flores, vistosas e frequentemente heterostílicas, são solitárias ou agrupadas em inflorescências axilares ou dispostas em cimeiras. As sépalas são basalmente conatas, persistentes nos frutos, e as pétalas são normalmente livres, unguiculadas, contortas nos botões e caducas. O androceu é constituído por 10 estames com dois tamanhos distintos e anteras dorsifixas e versáteis. O ovário é 5-carpelar e 5-locular e os frutos são cápsulas loculicidas com sementes ovoides lateralmente compressas (adaptado de Lourteig 1994; Aymard \& Berry 2003; Fiaschi \& Conceição 2005). Oxalis é o maior gênero da família, com ca. 500 espécies morfologicamente diversas e com distribuição cosmopolita (Mabberley 2008; Gardner et al. 2012). No Brasil ocorrem ca. 100 espécies, distribuídas por todos os estados brasileiros (BFG 2015). No estado do Pará ocorrem 11 espécies, enquanto nas cangas da Serra dos Carajás foram registradas duas espécies de Oxalis.

\footnotetext{
${ }^{1}$ Museu Paraense Emílio Goeldi, Prog. Capacitação Institucional, Campus de Pesquisa, Coord. Botânica, Av. Perimetral 1901, Terra Firme, 66077-830, Belém, PA, Brasil

${ }^{2}$ Universidade Federal de Santa Catarina, Depto. Botânica, Centro de Ciências Biológicas, Trindade, 88040-900, Florianópolis, SC, Brasil.

${ }^{3}$ Autor para correspondência. climbiehall@yahoo.com.br
} 


\section{Chave de identificação das espécies de Oxalis das cangas da Serra dos Carajás}

1. Folhas igualmente distribuídas ao longo dos ramos; pedúnculo 2,2-4,7 cm compr.; lacínios da corola róseos; cápsulas ovoides, recobertas por tricomas glandulares 1.1. Oxalis barrelieri

1'. Folhas predominantemente concentradas no ápice dos ramos; pedúnculo 0,7-2 cm compr.; lacínios da corola amarelos; cápsulas elipsoides, glabras 1.2. Oxalis mucronulata

1.1. Oxalis barrelieri L., Sp. Pl., ed. 2. 1: 624. 1762. Figs. 1a-d; 2a-c

Erva até $70 \mathrm{~cm}$ alt. Ramos jovens glabrescentes. Folhas alternas, espiraladas, pinadas, 3 -folioladas, folhas igualmente distribuídas ao longo dos ramos; pecíolo 2,3-2,7 cm compr., piloso; peciólulos ca. $1 \mathrm{~mm}$ compr.; folíolos verdes, discolores, adaxialmente glabros, abaxialmente glabrescentes a esparso-pubescentes, trulados a elípticos, base cuneada a arredondada, ápice cuneado a arredondado; folíolo central 1,3-2,5 $\times 0,6-1,7 \mathrm{~cm}$; laterais $1,5-2,2 \times 0,8-1,4 \mathrm{~cm}$. Inflorescência cimeira dicasial, 10-14-flora; pedúnculo 2,2-4,7 cm compr., pubescente. Flores brevistilas com pedicelo 1-2 cm compr., glabro a pubérulo; sépalas verdes, livres, $2-5 \times 0,5-1$ $\mathrm{mm}$, lanceoladas, pubescentes; pétalas $4-5 \mathrm{~mm}$ compr., internamente pubérulo-glandulares, tubo internamente amarelo-alaranjado; lacínios róseos a alvos; estames curtos 1,5-2 mm compr., longos 2,5-3 mm compr., anteras dorsifixas, versáteis, ca. $0,1 \mathrm{~mm}$ compr., elípticas; ovário ca. $1 \mathrm{~mm}$ compr., ovoide, glabro, ginóforo 2-2,5 mm compr., estiletes 1-1,2 mm compr., estigmas 5, curvos no ápice, papilosos. Flores medistilas e longistilas não vistas. Cápsulas $0,5-0,8 \times 0,3-0,4 \mathrm{~cm}$, ovoides, piloso-glandulares.

Material selecionado: Parauapebas [Canaã dos Carajás], Área do Parque botânico, 21.IV.1989, fl. e fr., M.F.F. Silva 458 (MG); Serra da Bocaina [Serra do Rabo-Norte], $6^{\circ} 18^{\prime} 55^{\prime}$ 'S, 49 54'09'W, 707 m, 18.XII.2010, fl. e fr., N.F.O. Mota et al. 1974 (BHCB).

Oxalis barrelieri possui ampla distribuição e é bastante plástica ao longo de sua distribuição (e.g., Lourteig 1994; Aymard \& Berry 2003; Fiaschi \& Conceição 2005; Sidwell 2012). A espécie pode ser diferenciada de $O$. mucronulata, também encontrada na Serra de Carajás, pelas folhas igualmente distribuídas ao longo dos ramos, pedúnculo 2,2-4,7 cm compr., lacínios da corola róseos e cápsulas ovoides, recobertas por tricomas glandulares. Outra espécie com afinidades morfológicas ocorre no estado do Pará, Oxalis cytisoides Mart. ex Zucc., com a qual $O$. barrelieri compartilha os lacínios das pétalas geralmente róseos. Estas espécies são bastante semelhantes e podem ser distintas uma da outra pelos folíolos geralmente glabrescentes a esparço-pubescentes com base cuneada a arredondada e ápice agudo a arredondado em $O$. barrelieri vs. folíolos pubescentes na face abaxial, com base aguda e ápice agudo a acuminado em $O$. cytisoides.

Espécie neotropical, distribuída dos Estados Unidos ao Paraguai, incluindo ilhas do Caribe, além de introduzida (também citada como invasora) na África e Polinésia (Lourteig 1994; Sidwell 2012). No Brasil, ocorre em todo o Centro-Oeste e Sudeste, além de Acre, Amazonas, Bahia, Pará, Paraná, Roraima e Santa Catarina (BFG 2015). Na Serra dos Carajás ocorre nas cangas da Serra da Bocaina. Espécie encontrada nas formações de canga, bordas de mata e áreas antropizadas.

1.2. Oxalis mucronulata Norlind, Ark. Bot. 20A(4): 10-11, pl. 1, f. 1. $1930 . \quad$ Fig. 1e-g

Erva até $50 \mathrm{~cm}$ alt. Ramos jovens pilosos. Folhas alternas a sub-opostas, espiraladas, pinadas, 3 -folioladas, predominantemente concentradas no ápice dos ramos; pecíolo 1,2-4,7 cm compr., piloso; peciólulos 0,5-1 $\mathrm{mm}$ compr.; folíolos verdes, discolores, pubescentes nas duas faces, deltados a ovados, base cuneada, ápice cuneado a arredondado; folíolo central 0,9-5,5 × 0,7-3,2 $\mathrm{cm}$; laterais 1,6-2,8 × 0,5-1,5 cm. Inflorescência cimeira dicasial, 10-12-flora; pedúnculo 0,7-2 cm compr., pubescente. Flores medistilas com pedicelo 1-3 cm compr., pubescente; sépalas verdes, livres, ca. 3-4 $\times 1 \mathrm{~mm}$, subuladas, pubescentes; pétalas 5-6 mm compr., internamente glabras, lacínios amarelos; estames curtos ca. $1 \mathrm{~mm}$ compr., longos 3-3,5 mm compr., anteras dorsifixas, versáteis, ca. 0,1 mm compr., elípticas; ovário ca. $1 \mathrm{~mm}$ compr., ovoide a piriforme, glabro, ginóforo ca. $0,2 \mathrm{~mm}$ compr., estiletes ca. $1 \mathrm{~mm}$ compr., estigmas 5 , curvos no ápice, papilosos. Flores brevistilas e longistilas não vistas. Cápsulas $2-3 \times 2-3 \mathrm{~mm}$, elipsoides, glabras.

Material selecionado: Parauapebas, N4-WS, 6 ${ }^{\circ} 04^{\prime 2} 22^{\prime \prime S}$, $50^{\circ} 11^{\prime} 42^{\prime \prime} \mathrm{W}, 24 . I I I .2012$, fl. e fr., A.J. Arruda et al. 820 (BHCB). Parauapebas [Marabá], estrada do estéril sul, as proximidades da Barragem, 6.II.1985, fl. e fr., O.C. Nascimento \& R.P. Bahia 1179 (MG). 


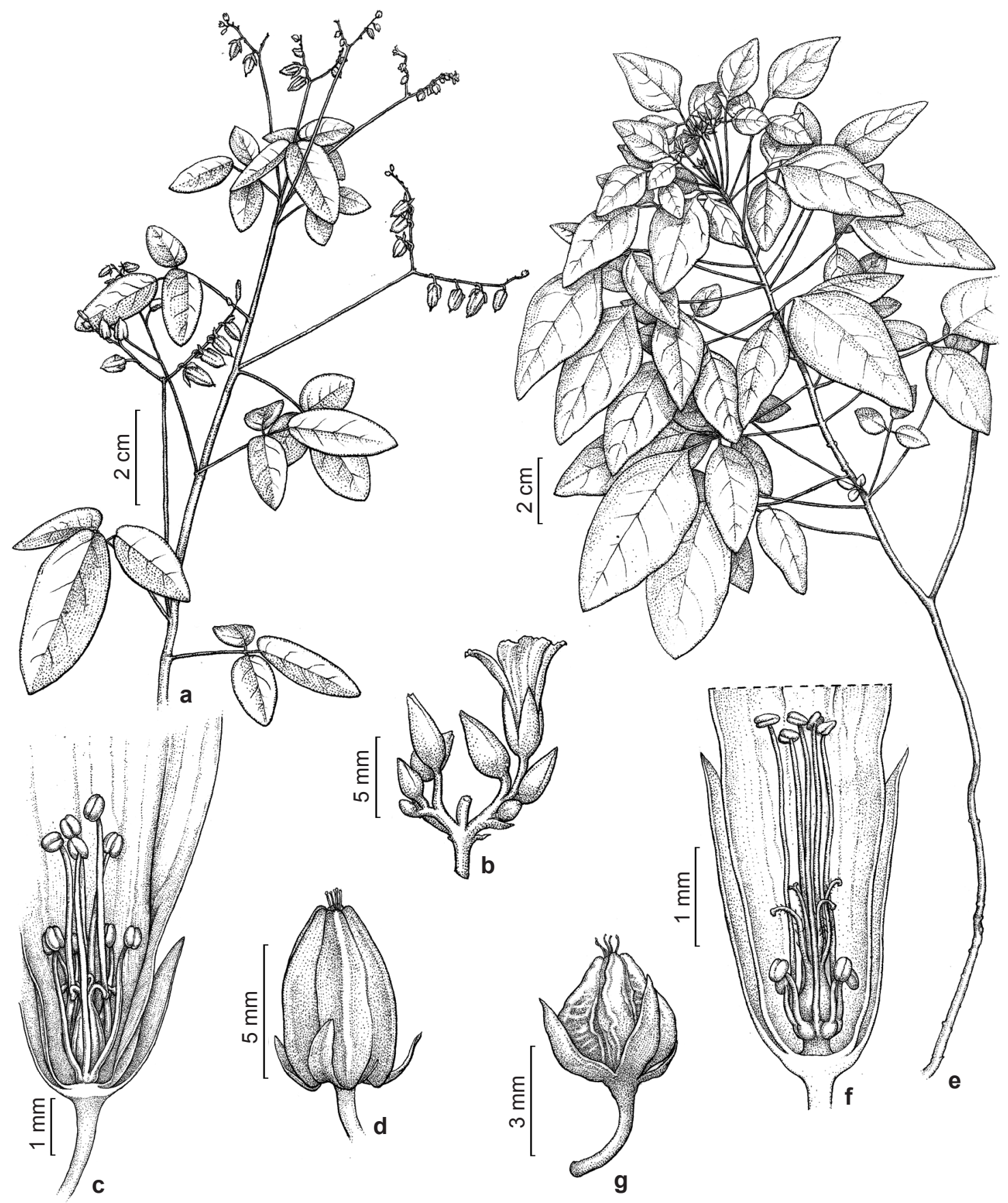

Figura 1 - a-d. Oxalis barrelieri - a. hábito; b. detalhe da inflorescência; c. flor brevistila (seção longitudinal); d. fruto (vista lateral). e-g. Oxalis mucronulata - e. hábito; f. flor medistila (seção longitudinal); g. fruto (vista lateral). Figure 1 - a-d. Oxalis barrelier - a. habit; b. detail of the inflorescence; c. short-styled flower (longitudinal section); d. fruit (side view). e-g. Oxalis mucronulata - e. habit; f. mid-styled flower (longitudinal section); g. fruit (side view). 

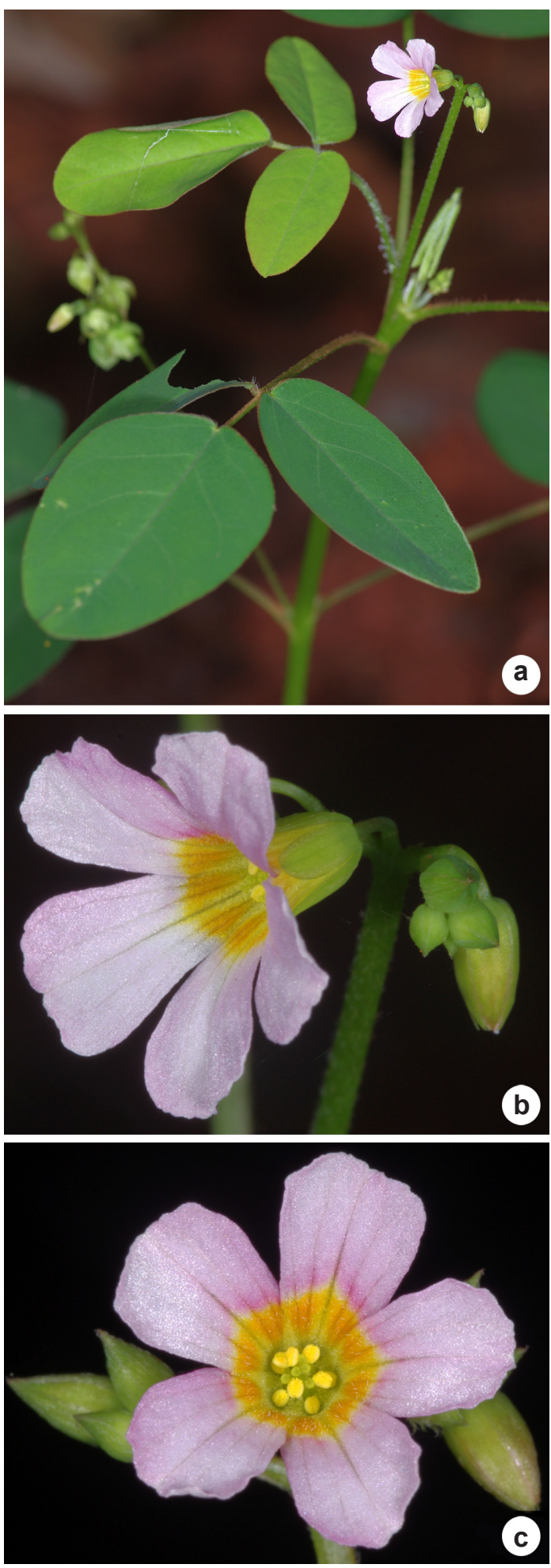

Figura 2-Oxalis barrelieri-a. detalhe do hábito; b. detalhe da inflorescência; c. flor (vista frontal). Fotos: C.F. Hall Figure 2 - Oxalis barrelieri - a. detail of the habit; b. detail of the inflorescence; c. flower (front view). Photos: C.F. Hall
Oxalis mucronulata só era conhecida no Brasil pelos dois espécimes citados por Lourteig (1994). Assim, as coletas de Carajás representam o terceiro registro para o Brasil. Os exemplares de Carajás exibem diferenças morfológicas do que foi descrito por Lourteig (1994), e quando comparada com o tipo da espécie, principalmente pelo ápice do folíolo arredondado ( $v s$. agudo a acuminado), pedúnculos curtos $0,7-2 \mathrm{~cm}$ compr. (vs. até $7 \mathrm{~cm}$ compr.) e cápsula ca. $3 \mathrm{~mm}$ compr. (vs. ca. $5 \mathrm{~mm}$ compr.). Oxalis mucronulata pode ser diferenciada de $O$. barrelieri pelas folhas predominantemente concentradas no ápice dos ramos, pedúnculo $0,7-2 \mathrm{~cm}$ compr., pétalas amarelas e cápsulas glabras e elípticas.

Espécie sul-americana, registrada no Brasil, Guiana e Venezuela (Lourteig 1994; Tropicos 2017). No Brasil ocorre apenas no Pará (BFG 2015). Na Serra dos Carajás ocorre na Serra Norte: N4. Espécie registrada em áreas de transição de canga e floresta ombrófila densa.

\section{Agradecimentos}

Agradecemos ao Museu Paraense Emílio Goeldi e ao Instituto Tecnológico Vale, a estrutura e apoio. Ao CNPq, a bolsa do Programa de Capacitação Institucional (MPEG/MCTI) concedida aos autores CFH e JM e a bolsa de Produtividade em Pesquisa a PF (processo 306228/2016-5). Aos curadores dos herbários BHCB, HCJS, IAN e MG, a disponibilização de material para a análise. Ao Dr. Pedro Viana e à Dra. Ana Maria Giulietti, coordenadores do projeto "Flora de Carajás", o convite. Ao projeto objeto do convênio MPEG/ITV/ FADESP (01205.000250/2014-10) e ao projeto aprovado pelo CNPq (processo 455505/2014-4), o financiamento. Ao ICMBio, especialmente ao Frederico Drumond Martins, a licença de coleta concedida e suporte nos trabalhos de campo. Ao Me. João Silveira, a confecção das ilustrações.

\section{Referências}

Aymard GA \& Berry PE (2003) Oxalidaceae. In: Berry PE, Yatskievych K \& Holst BK (eds.) Flora of the Venezuelan Guayana. Myrtaceae-Plumbaginaceae. Vol. 7. Missouri Botanical Garden Press, St. Louis. Pp. 619-625.

BFG - The Brazil Flora Group (2015) Growing knowledge: an overview of seed plant diversity in Brazil. Rodriguésia 66: 1085-1113.

Fiaschi P, Abreu MC, Filho LAFS \& Monteiro NP (2013) Oxalidaceae. In: Martinelli G \& Moraes MA (eds.) Livro vermelho da flora do Brasil. Instituto de 
Pesquisas Jardim Botânico do Rio de Janeiro, Rio de Janeiro. Pp. 823-828.

Fiaschi P \& Conceição AA (2005) Oxalidaceae. In: Wanderley MGL, Shepherd GJ, Melhem TS \& Giulietti AM (coords.) Flora Fanerogâmica do Estado de São Paulo. FAPESP, Rima, São Paulo. Vol. 4, pp. 301-315.

Gardner AG, Vaio M, Guerra M \& Emshwiller E (2012) Diversification of the American bulb-bearing Oxalis (Oxalidaceae): dispersal to North America and modification of the tristylous breeding system. American Journal of Botany 99: 152-164.

Lourteig A (1980) Oxalidaceae In: Flora of Panamá. Annals of the Missouri Botanical Garden 67: 823-850.

Lourteig A (1994) Oxalis L. Subgênero Thamnoxys (Endl.) Reiche emend. Lourt. Bradea 7: 1-199.

Mabberley DJ (2008) Mabberley's plant book. A portable dictionary of plants, their classification and uses. $3^{\text {a }}$ ed. Cambridge University Press, Cambridge. 1040p.

Progel A (1877) Oxalideae. In: Martius CFP \& Eichler AG (eds.) Flora Brasiliensis. Munchen, Wien, Leipzig, Monachii. Vol. 12, pp. 473-520, tab. 102-116.

Sidwell K (2012) Oxalidaceae. In: Davidse G, Sousa M, Knapp S \& Chiang F (eds.) Vitaceae a Geraniaceae. Flora Mesoamericana. Missouri Botanical Garden. Disponível em $<$ http://www.tropicos.org/Name/42 000267 ? projectid $=3$ \&langid $=66>$. Acesso em 27 março 2017.

Stevens PF [2001 onwards]. Angiosperm Phylogeny Website. Version 9, June 2008 [and more or less continuously updated since]. Disponível em $<$ http:// www.mobot.org/MOBOT/research/APweb/>. Acesso em 27 março 2017.

Tropicos (2017) Missouri Botanical Garden. Disponível em $<$ http://www.tropicos.org > . Acesso em 27 março 2017.

Lista de exsicatas

Arruda AJ 820 (1.2). Nascimento OC 1179 (1.2). Mota NFO 1193 (1.1), 1974 (1.1). Silva MFF 458 (1.1). 